Informatika i sistemy upravleniya. - 2017. - No. 2(52). - P. 3-11.

Bobkov V.A. (bobkov@dvo.ru;), Kudryashov A.P.

Institute of Automation and Control Processes

\title{
RECONSTRUCTION AND VISUALIZATION OF SPATIAL SCENES USING A GLOBAL POINT-BASED MODEL
}

The article suggests technology of formation and visualization of spatial static scene on a sequence of images produced by a moving stereo camera. The technology includes the algorithmic processing of the initial data in the calibration images stage, production of a dense set of 3D points, combinations of various kinds in a unified global point model and rapid visualization based on the use of "surface splats". Our paper presents the results of computational experiments with the simulating scenes, prepared by the simulator.

Keywords: 3D reconstruction, point-based model, visualization, surface splat.

DOI: $10.22250 /$ isu.2017.52.3-11

For citation:

Bobkov V.A. , Kudryashov A.P.

RECONSTRUCTION AND VISUALIZATION OF SPATIAL SCENES USING A GLOBAL POINT-BASED MODEL // Informatika i sistemy upravleniya. - 2017. - No. 2(521). - P. 3-11. 